\title{
Analisis Performansi Jaringan OSPF Menggunakan Metode Translasi NAT-PT
}

\section{The Performance Analysis of OSPF Network by NAT-PT Translation Method}

\author{
Maryanto Firman Fauzi ${ }^{1, *}$, Kukuh Nugroho ${ }^{2}$ \\ ${ }^{1,2}$ Program Studi S1 Teknik Telekomunikasi, \\ Fakultas Teknik Telekomunikasi dan Elektro, Institut Teknologi Telkom Purwokerto \\ Jl D.I Panjaitan no.128, Purwokerto 53147, Jawa Tengah, Indonesia \\ 1,*Penulis korespondensi: 4101110@ittelkom-pwt.ac.id \\ ${ }^{2}$ kukuh@ittelkom-pwt.ac.id
}

Received on 27-06-2019, accepted on 01-08-2019, published 06-08-2019

Abstrak

Pertumbuhan pengguna Internet semakin lama bertambah banyak. Pengalokasian alamat IP versi 4 (IPv4) sudah tidak mampu lagi menampung pertumbuhan pengguna Internet tersebut. Setiap user yang ingin menggunakan Internet harus terhubung ke jaringan dengan menggunakan alamat IP public. Untuk memenuhi kebutuhan alamat IP tersebut dibutuhkan IPv6 karena IPv6 menggunakan jumlah bit yang lebih banyak yaitu 128-bit. Antar perangkat yang menggunakan IPv4 dan IPv6 tidak dapat langsung dihubungkan. Oleh karena itu dibutuhkan metode translasi. Pada penelitian ini akan diteliti performansi jaringan dimana metode translasi yang digunakan adalah NAT-PT (Network Address Translation - Protocol Translation) menggunakan routing protocol OSPF (Open Short Path Firts). Penelitian ini menggunakan parameter performansi jaringan diantaranya adalah throughput, delay, dan packet loss. Berdasarkan hasil penelitian, rata - rata throughput pada file sharing sebesar 6,243 Mbps dan pada video streaming sebesar 0,279 Mbps. Sedangkan rata - rata delay pada file sharing sebesar $1,033 \mathrm{~ms}$ dan pada video streaming sebesar 2,382 ms. Kemudian rata-rata packet loss video streaming sebesar $0,0000225 \%$.

Keywords: IPv4, IPv6, Metode Translasi, NAT-PT, OSPF.

\section{Abstract}

The growth of Internet users is increasing over time. The allocation of IP address version 4 (IPv4) is no longer able to accommodate the growth of Internet users. Every user who wants to use the Internet must connect to the network using a public IP address. To meet the needs of these IP addresses, IPv6 is needed because IPv6 uses a more number of bits, namely 128bits. Devices that use IPv4 and IPv6 cannot be directly connected. Therefore, a translation method is needed. In this study, network performance will be investigated where the translation method used is NAT-PT (Network Address Translation - Protocol Translation) using the OSPF (Open Short Path Firsts) routing protocol. This study uses network performance parameters including throughput, delay, and packet loss. Based on the research results, the average throughput for file sharing is $6.243 \mathrm{Mbps}$ and for video streaming is 0.279 Mbps. While the average delay in file sharing is $1.033 \mathrm{~ms}$, and video streaming is $\mathbf{2 . 3 8 2} \mathrm{ms}$. Then the average packet loss of video streaming is $\mathbf{0 . 0 0 0 0 2 2 5 \%}$.

Keywords: IPv4, IPv6, Metode Translasi, NAT-PT, OSPF 



\section{Pendahuluan}

Perkembangan zaman saat mengakibatkan semakin banyak orang yang menggunakan perangkat komputer dan perangkat lain yang terhubung dengan internet. Hal ini mengakibatkan kebutuhan alamat IP semakin meningkat pada jaringan internet. Alamat IPv4 dan IPv6 merupakan protokol internet yang berlaku. IPv4 (Internet Protocol version 4) merupakan pengalokasian IP yang digunakan saat ini, IPv4 menggunakan format 32 bit dengan jumlah pengalamatan 232 atau 4,292 x 109 [1]. Jumlah pengalamatan pada IPv4 sangat terbatas untuk menangani kebutuhan pengalokasian IP saat ini. Sedangkan pada data Internet Assigned Number Authority (IANA) menyatakan bahwa hanya tersisa 7\% pengalamatan pada IPv4 di tingkat dunia [2]. Dengan keterbatasan IPv4, munculah teknologi pengalokasian IP yaitu IPv6 (Internet Protocol version 6) atau bisa disebut sebagai Internet Procotol Next Generation. IPv6 menggunakan format 128-bit dengan jumlah pengalamatan x2128 atau 3,402 x 1038 [1]. Jumlah alamat IPv6 lebih banyak dibandingkan dengan IPv4 dan jumlah alamat ini lebih dari cukup digunakan untuk alamat perangkat diseluruh dunia [3]. Dengan adanya IPv6, IPv4 dapat digantikan dengan IPv6. Tetapi, pengalokasian IP menggunakan IPv4 sudah sangat mendominasi sehingga tidak mungkin untuk segera digantikan dengan IPv6. Sehingga pergantian IPv4 dengan IPv6 digantikan secara bertahap. Dengan adanya IPv6, IPv4 dapat digantikan dengan IPv6. Penggunaan IPv6 diperlukan perubahan dalam infrastruktur yang menyebabkan implementasi IPv6 mengantikan IPv4 belum terlaksana sepenuhnya. Masa ini disebut sebagai masa transisi. Dengan adanya masa transisi, penggunaan alamat yang masih menggunakan IPv4 pada perangkat jaringan tidak dapat berkomunikasi dengan perangkat jaringan yang sudah menggunakan alamat IPv6. Agar perangkat IPv4 dan IPv6 dapat berkomunkasi dibutuhkan metode transisi IPv6 antara lain Dual Stack, Translasi dan Tunneling [3].

NAT-PT (Network Address Translation - Protocol Translation) merupakan salah satu metode tranlasi yang dapat digunakan. NAT-PT merupakan metode yang dapat mengubah format header dari IPv4 ke format header IPv6 dan sebaliknya [4]. Metode ini mendukung suatu perangkat jaringan yang masih menggunakan pengalamatan IPv4 untuk berkomunikasi dengan perangkat jaringan yang sudah menggunakan pengalamatan IPv6 [3]. Dalam penelitian ini akan menganalisa tentang metode translasi NAT-PT dengan parameter QoS yaitu throughput, delay dan packet loss. Protokol routing yang akan digunakan dalam penelitian ini yaitu OSPF (Open Shortest Path First).

\section{KaJian PUSTAKa}

Penelitian yang berkaitan dengan penggunaan metode translasi telah dilakukan oleh Hossain M. A. [4]. Penelitian tersebut melakukan perbandingan antara Dual Stack, Tunneling dan metode translasi menggunakan simulasi jaringan Cisco Packet Tracer. Penelitian tersebut memaparkan beberapa metode dalam menguji interkoneksi IPv4 dan IPv6. Penelitian tersebut memperlihatkan hasil data mengenai throughput, latency dan packet loss dengan menggunakan metode pengujian ICMP. Berdasarkan hasil penelitian tersebut diperoleh data bahwa metode tunneling mendapatkan throughput dan latency yang baik dengan packet loss yang rendah. Sedangkan penggunaan metode Dual stack mendapatkan throughput dan latency yang cukup baik dengan packet loss yang cukup tinggi daripada penggunaan metode tunneling. Penggunaan NAT-PT mendapatkan nilai throughput dan latency yang kurang baik dengan packet loss yang tinggi.

Penelitian juga dilakukan oleh Sharma S. tentang metode translasi pada jaringan IPv4 dan IPv6 [5]. Penelitian tersebut melakukan perbandingan metode transisi yaitu Dual Stack, Tunneling dan metode translasi. Penelitian tersebut memperlihatkan hasil data mengenai throughput, delay dan packet loss dengan menggunakan software simulasi jaringan OPNET (Optimized Network Engineering Tool) versi 16. Pengujian data yang dilakukan dalam penelitian tersebut adalah FTP dan HTTP. Dari penelitian tersebut didapatkan bahwa throughput yang didapatkan yaitu 200 bit per detik untuk Tunneling dan 100 bit per detik untuk NAT-PT dan Dual Stack. Pada packet loss didapatkan NAT-PT dan Dual Stack mengalami packet drop sekitar 1,4 paket per detik dan Tunneling mengalami packet drop sekitar 1.0 paket per detik.

Penelitian mengenai teknologi yang dapat digunakan pada saat masa transisi IP dari IPv4 ke IPv6 dilakukan oleh Li XiaoHong [6]. Penelitian ini menjelaskan tentang metode yang dapat digunakan pada masa transisi IPv4 ke IPv6. Teknologi transisi fokus pada pemecahan masalah dan bagaimana mencapai jaringan IPv6 dan mendapatkan transisi yang mulus dari dalam jaringan IPv4. Teknologi transisi dasar adalah Dual Stack, Tunneling, dan NAT-PT. 


\section{Metode Penelitian}

Pada proses pengerjaan penelitian dilakukan dengan menggunakan tahapan perancangan dan pengujian jaringan di laboratorium komputer dan aplikasi Institut Teknologi Telkom Purwokerto. Dalam pengerjaan penelitian ini ada beberapa hal yang dilakukan antara lain hardware, software, konfigurasi jaringan, pengujian jaringan, pengambilan data sesuai skenario dan analisis data yang didapatkan. Kebutuhan hardware yang dilakukan untuk melakukan penelitian diantaranya adalah tiga PC (Personal Computer) dan satu laptop dengan rincian satu unit PC sebagai server, satu unit PC sebagai simulator GNS3 dan satu unit laptop sebagai client. Kebutuhan software sebagai alat untuk melakukan penelitian diantaranya adalah GNS3 (Graphic Network Simulation 3) sebagai software emulator untuk membangun jaringan simulasi, VLC Media Player sebagai software pemutar video berbasis open source, dimana dalam hal penyetingan jenis protokol transportnya dapat dikonfigurasi secara manual, software Wireshark sebagai software network protocol analyzer yang digunakan untuk melihat jenis data yang akan dianalisa, dan Windows Explorer merupakan software file manager bawaan Windows yang digunakan untuk mengakses file sharing antara server dan client.

\section{A. Alur Penelitian}

Alur penelitian dalam mengumpulkan data penelitian dijelaskan dalam bentuk flowchart pengerjaan penelitian berkaitan dengan proses analisis performansi protokol routing OSPF dengan metode translasi NAT-PT secara keseluruhan yang ditunjukkan pada Gambar 1.

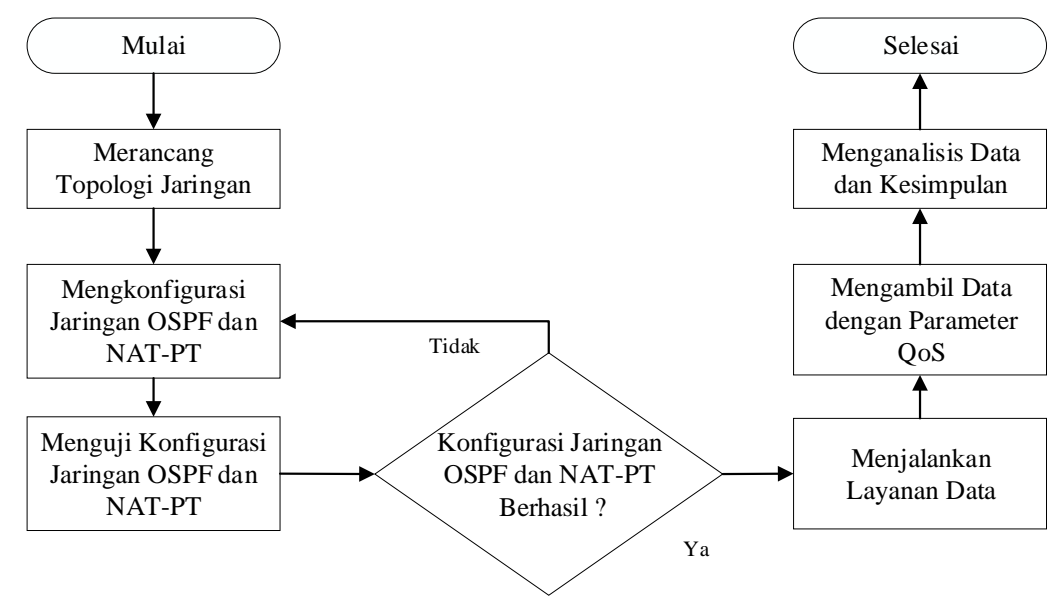

Gambar 1. Flowchart Penelitian

Pada Gambar 1 menunjukkan bahwa dalam mencapai tujuan penelitian ini, pertama dengan merancang topologi jaringan. Suatu rancangan tentang bagaimana topologi yang digunakan dan disimulasikan pada software simulasi GNS3. Tahap kedua dengan mengkonfigurasi jaringan OSPF dan NAT-PT. Pada tahap ini topologi jaringan dibuat sampai topologi dapat digunakan. Konfigurasi yang digunakan yaitu IPv4, IPv6, protokol routing OSPF, dan mode translasi NAT-PT. Protokol routing OSPF berperan sebagai penghubung antar router. Dan mode translasi sebagai penghubung antara IPv4 dan IPv6. Tahap ketiga menguji konfigurasi jaringan dengan cara menjalankan simulasi. Apabila memang terjadi kesalahan maka akan langsung kembali ke tahap mengkonfigurasi jaringan. Setelah itu masuk ke tahap keempat merupakan proses dimana topologi menjalankan file dan video dan tahap kelima mengambil data sesuai dengan parameter QoS yaitu throughput, delay, dan packet loss. Setelah mengambil data sesuai dengan QoS, maka data tersebut akan diolah menjadi hasil data. Tahapan merupakan akhir dari proses penelitian. 


\section{B. Merancang Topologi Jaringan}

Pada penelitian ini topologi jaringan yang digunakan pada proses penelitian dijelaskan pada Gambar 2. Topologi jaringan nantinya akan diimplementasikan dengan menggunakan software GNS3.

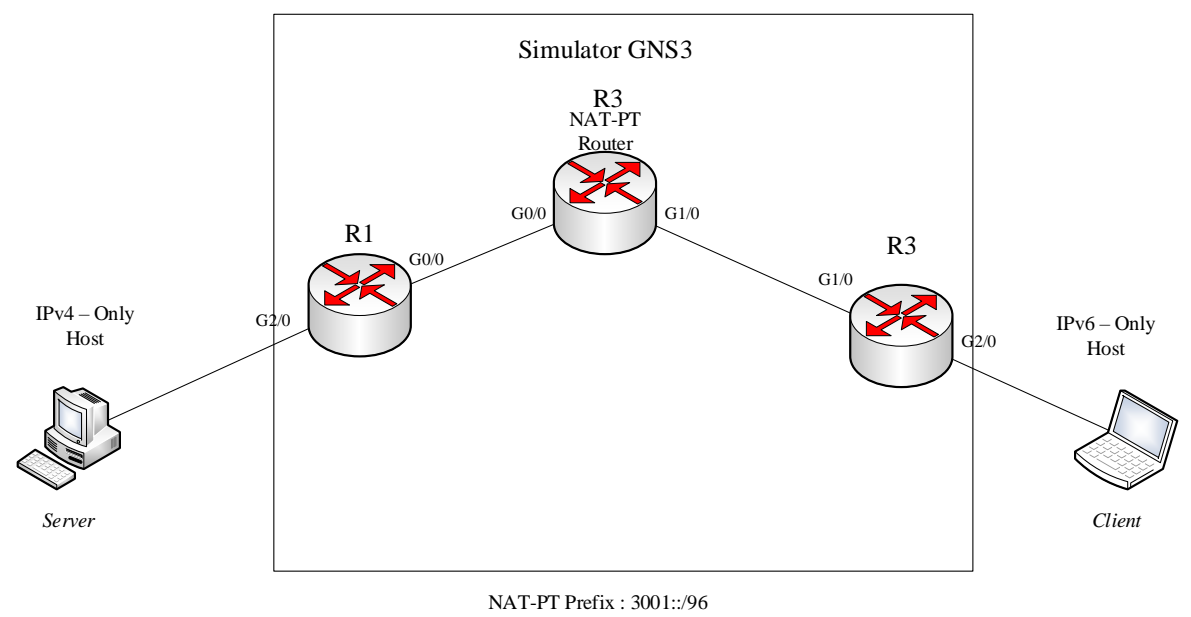

Gambar 2. Topologi Jaringan dengan Protokol Routing OSPF dengan NAT-PT

Perancangan topologi menggunakan dua PC dan satu Laptop. Satu PC sebagai server, satu PC sebagai simulator GNS3 dan satu Laptop sebagai client. Pada simulator GNS3 menggunakan tiga router yang menghubungkan server dan client seperti Gambar 2. Topologi tersebut digunakan pada penelitian untuk menganalisis performansi protokol routing OSPF dengan metode translasi NAT-PT IPv4/IPv6. Konfigurasi topologi juga menggunakan protokol routing OSPF. Pada simulator GNS3 menggunakan tiga router yaitu $\mathrm{R} 1$, R2, dan R3 yang dihubungkan dengan konfigurasi protokol routing OSPF pada IPv4 dan OSPFv3 pada IPv6. Dari topologi tersebut menggunakan IP seperti pada Tabel 1.

Tabel 1. Tabel Pengalamatan IP

\begin{tabular}{|c|c|c|}
\hline Perangkat & Interface & Alamat IP \\
\hline R1 & G2/0 & 192.168 .1 .1 \\
\hline & $\mathrm{G} 0 / 0$ & 192.168 .2 .1 \\
\hline R2 & G0/0 & 192.168 .2 .2 \\
\hline R3 & G1/0 & $1001:: 2$ \\
\hline & $\mathrm{G} 1 / 0$ & $1001:: 3$ \\
\hline PC 1 & G2/0 & $2001:: 3$ \\
\hline PC 2 & - & 192.168 .1 .50 \\
\hline
\end{tabular}

Tabel 1 menjelaskan pengalaman IP yang digunakan menggunakan IPv4 dan IPv6. Pada Tabel 1 menjelaskan pada R1 menggunakan dua interface yaitu G2/0 dengan alamat IP 192.168.1.1 yang terhubung dengan PC server dan interface G0/0 dengan alamat IP 192.168.2.1 yang terhubung dengan R2. R2 menggunakan dua interface yaitu G0/0 dengan alamat IP 192.168.2.2 yang terhubung dengan R1 dan interface G1/0 menggunakan alamat IP 1001::2 yang terhubung dengan R3. Pada R2 menggunakan alamat IPv4 dan IPv6 karena R2 akan menggunakan metode tranlasi NAT-PT sebagai interkoneksi antar IPv4 dan IPv6. R3 menggunakan dua interface yaitu G1/0 dengan alamat IP 1001::3 yang terhubung dengan R2 dan G2/0 dengan alamat IP 1001::3 yang terhubung dengan laptop client. Laptop client menggunakan alamat IPv6 yaitu 2001::50 dan PC server menggunakan alamat IPv4 yaitu 192.168.1.50.

\section{Topologi Jaringan}

Gambar topologi jaringan yang sudah dirancang dan juga alamat IP yang digunakan untuk proses pengambilan data dilakukan dengan menggunakan software simulasi GNS3. Konfigurasi OSPF dan OSPFv3 terlihat pada penjelasan Gambar 3 berikut. 


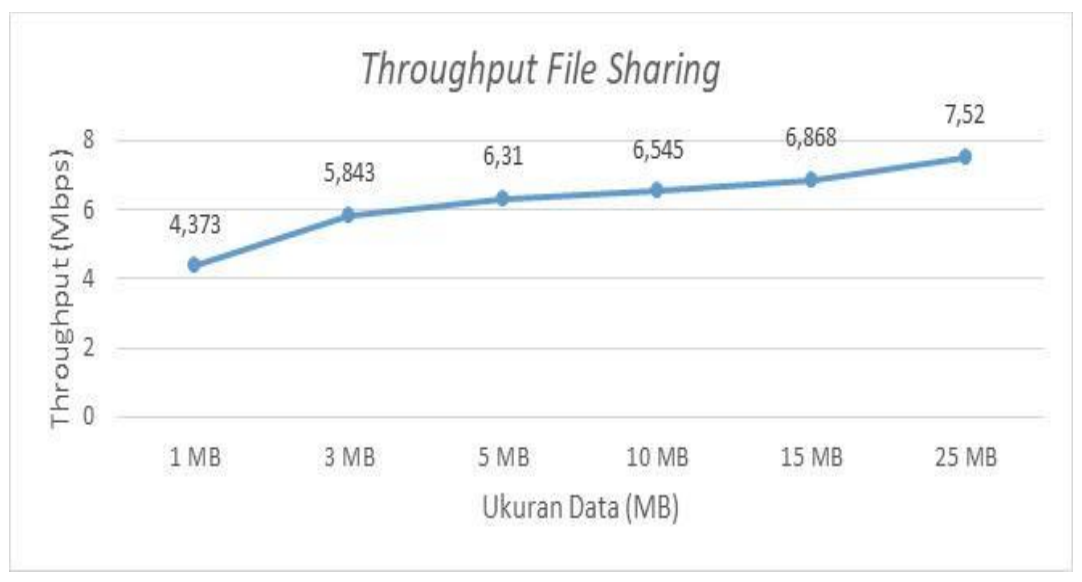

Gambar 5. Grafik Throughput File Sharing

Pada Gambar 5 menunjukan grafik perubahan throughput file sharing terhadap perubahan ukuran data. Pada penelitian ini, nilai throughput pada layanan file sharing dengan ukuran data $1 \mathrm{MB}$ mempunyai nilai 4,373 Mbps sedangkan pada ukuran data 3 MB mempunyai nilai throughput 5,843 Mbps kemudian untuk ukuran data $5 \mathrm{MB}$ memiliki jumlah nilai throughput 6,31 Mbps lalu untuk ukuran $10 \mathrm{MB}$ memiliki jumlah throughput 6,545 Mbps sedangkan untuk ukuran data 15 MB memiliki nilai throughput 6,868 Mbps dan untuk data $25 \mathrm{MB}$ memiliki nilai throughput 7,52 Mbps. Berdasarkan hasil penelitian ini, nilai throughput yang berbeda pada file sharing disebabkan oleh waktu pengiriman paket yang berbeda sedangkan ukuran paket yang dikirimkan sama.

Pada layanan video streaming didapatkan hasil penelitian parameter throughput jaringan OSPF dengan metode tranlasi NAT-PT menggunakan software VLC. Adapun grafik pada Gambar 6 perbandingan perbandingan variasi beban trafik terhadap throughput video streaming pada jaringan OSPF dengan metode tranlasi NAT-PT.

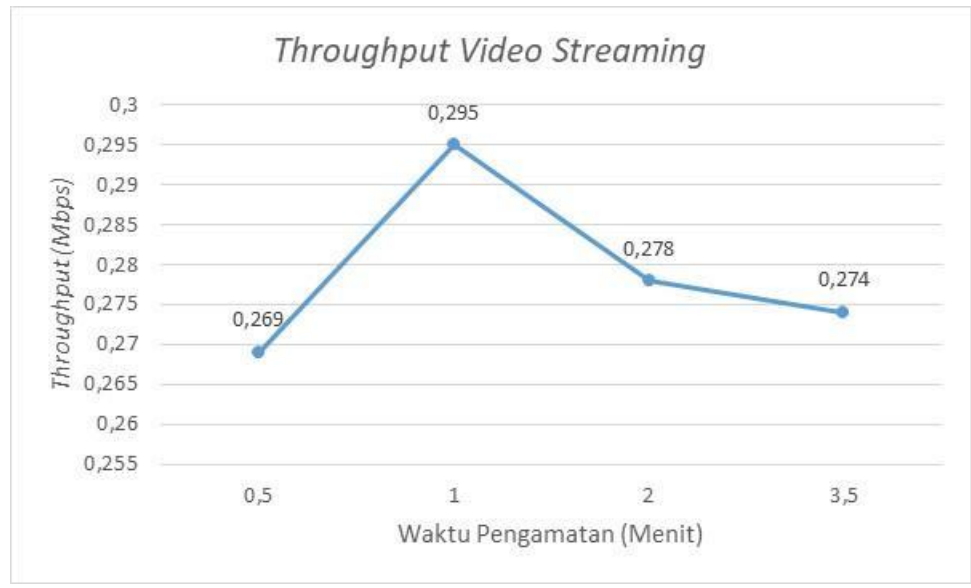

Gambar 6. Grafik throughput video streaming

Nilai rata-rata throughput pada variasi beban trafik dihasilkan nilai throughput tertinggi terdapat pada waktu pengamatan 1 menit yaitu sebesar 0,295 Mbps/s. Sedangkan untuk rata-rata yang dihasilkan dari variasi waktu pengamatan sebesar 0,279 Mbps/s. Dari Gambar 6 terlihat bahwa semakin besar atau semakin kecil beban trafik yang digunakan tidak mempengaruhi throughput selama penggunaan aplikasi video streaming.

\section{Analisis Delay}

Analisis delay diperoleh dari perhitungan jumlah paket data yang telah dikirim kemudian dibagi dengan waktu pada saat pengiriman data. Delay berkaitan dengan waktu tunda karena proses transmisi paket dari pengirim menuju penerima. Adapun yang mempengaruhi delay itu sendiri adalah bandwidth jaringan, 
kecepatan media transmisi, proses pembentukan paket, dan kehandalan perangkat dalam memproses data. Nilai delay yang berbeda pada file sharing disebabkan oleh waktu pengiriman paket yang berbeda. Adapun grafik perbandingannya ditampilkan pada Gambar 7.

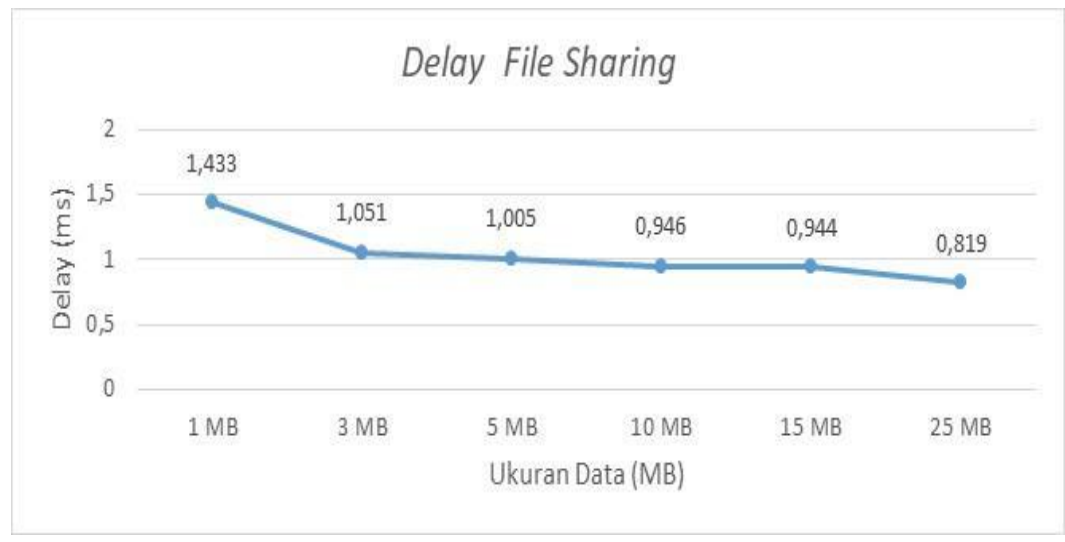

Gambar 7. Grafik Delay File Sharing

Berdasarkan Gambar 7 terlihat bahwa pada saat menggunakan layanan file sharing. Pada penelitian ini, nilai delay pada layanan file sharing dengan ukuran file $1 \mathrm{MB}$ mempunyai nilai 1,433 ms sedangkan pada ukuran file $3 \mathrm{MB}$ mempunyai nilai delay 1,051 ms, kemudian untuk ukuran file $5 \mathrm{MB}$ memiliki nilai delay $1,005 \mathrm{~ms}$, lalu untuk ukuran $10 \mathrm{MB}$ memiliki jumlah delay $0,946 \mathrm{~ms}$, sedangkan untuk ukuran file $15 \mathrm{MB}$ memiliki nilai delay $0,944 \mathrm{~ms}$ dan untuk ukuran file $25 \mathrm{MB}$ memiliki nilai delay 0,819 ms. Berdasarkan hasil penelitian ini didapatkan hasil bahwa semakin besar nilai throughput yang dihasilkan oleh suatu jaringan maka nilai delay yang dihasilkan kecil. Sedangkan jika nilai throuhput pada sebuah jaringan bernilai kecil maka delay pada saat pengiriman paket data akan bernilai besar. Nilai delay berbanding terbalik dengan nilai throughput. Berdasarkan standarisasi menurut TIPHON untuk delay, hasil yang didapatkan pada penelitian ini termasuk pada kategori sangat bagus karena kurang dari $150 \mathrm{~ms}$.

Pada layanan video streaming didapatkan hasil penelitian parameter delay jaringan OSPF dengan metode tranlasi NAT-PT menggunakan software VLC. Adapun Gambar grafik 8 menjelaskan perbandingan variasi beban trafik terhadap delay untuk seluruh konfigurasi jaringan OSPF dengan metode tranlasi NAT-PT.

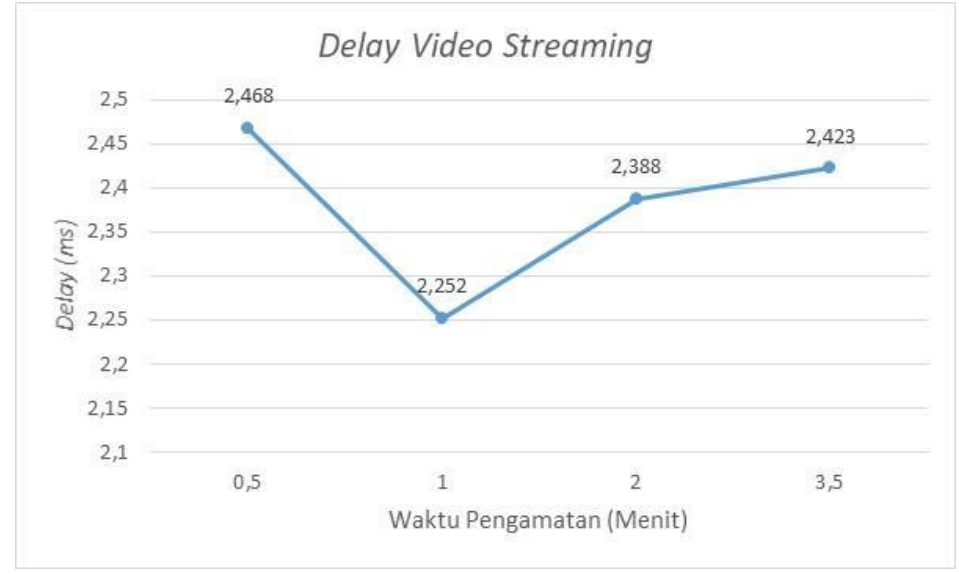

Gambar 8. Grafik Delay Video Streaming

Berdasarkan grafik pada Gambar 8 nilai delay terendah terdapat pada waktu pengamatan 1 menit sebesar 2,252 ms, sedangkan nilai delay terbesar pada saat beban trafik 30 detik yang bernilai 2,468 ms. Dari gambar 8 dihasilkan bahwa pada saat menggunakan layanan video streaming memiliki rata-rata delay 2,383 $\mathrm{ms}$, Berdasarkan standarisasi menurut TIPHON untuk delay, hasil yang didapatkan pada penelitian ini termasuk pada kategori sangat bagus karena kurang dari $150 \mathrm{~ms}$. 


\section{Analisis Packet Loss}

Packet loss merupakan banyaknya paket yang hilang dalam pengiriman data sehingga data yang diterima tidak sama lagi dengan data yang dikirim. Analisis packet loss sangat dibutuhkan agar dapat mengetahui performansi dari kinerja translasi NAT-PT pada setiap layanan yang digunakan. Pada layanan file sharing tidak terdapat packet loss. Hal ini dikarenakan pada sistem komunikasi connection oriented, data yang tidak sampai dikirimkan ulang atau retrasmitted dan tidak mengakibatkan packet loss.

Pada layanan video streaming didapatkan hasil penelitian parameter packet loss jaringan OSPF dengan metode tranlasi NAT-PT IPv4/IPv6 menggunakan software VLC. Nilai rata-rata packet loss memiliki nilai 0,000225 . Pada variasi waktu pengamatan 0,5 menit dan 1 menit memiliki persentase packet loss sebesar 0 $\%$ dan pada beban trafik 2 menit dan 3,5 menit memiliki persentase 0,0004\% dan 0,0005. Hasil pengukuran nilai packet loss dijelaskan pada keterangan gambar 9 berikut.

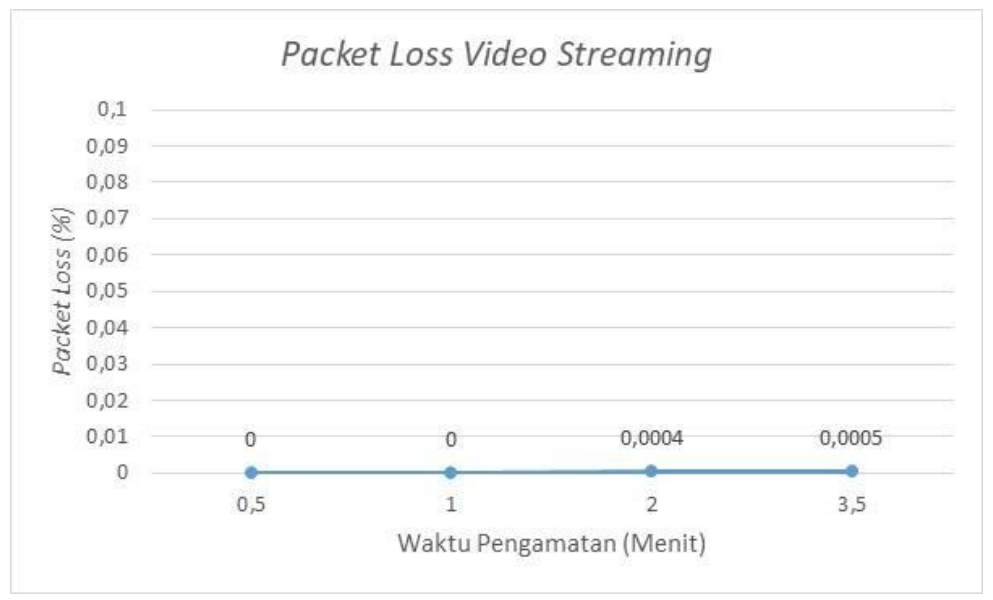

Gambar 8. Grafik Packet Loss Video Streaming

Berdasarkan data pada Gambar 8, terlihat bahwa pada saat menggunakan layanan video streaming memilik persentase packet loss sebesar $0,00025 \%$. Hasil pengukuran mendapatkan nilai perbandingan dengan data standarisasi TIPHON dimasukkan dalam kategori sangat bagus.

\section{KESIMPULAN}

Berdasarkan pembahasan mengenai hasil analisis penelitian jaringan OSPF dengan metode tranlasi NATPT IPv4/IPv6 diperoleh hasil bahwa semakin besar beban trafik terhadap layanan file sharing sangat berpengaruh terhadap nilai throughput dan delay. Sedangkan variasi beban trafik waktu terhadap video streaming tidak terlalu berpengaruh terhadap nilai throughput, delay dan packet loss. Perbandingan hasil nilai throughput pada implementasi layananan file sharing dan video streaming adalah sebesar $6,243 \mathrm{Mbps}$ dan 0,279 Mbps. Sedangkan untuk perbandingan nilai delay diperoleh hasil sebesar $1.033 \mathrm{~ms}$ untuk layanan file sharing dan $2,383 \mathrm{~ms}$ untuk video streaming. Semua hasil pengujian jaringan OSPF berdasarkan parameter uji dengan menggunakan mekanisme translasi NAT-PT diperoleh hasil yang bagus sesuai dengan standarisasi THIPON. 


\section{Daftar Pustaka}

[1] Diwi, A. I., Mangkudjaja, R. R., Wahidah, I., (2014). Analisis Kualitas Layanan Video Live Streaming pada Jaringan Lokal Universitas Telkom. Buletin Pos dan Telekomunikasi, 12(3), 207-216

[2] Dunmore, M., (2005). An IPv6 Deployment Guide. European: The 6NET Consortium.

[3] Elidjen. Tahun, S., Santoso, B., \& Citronegoro, Cipto., (2010). Simulasi Penggunaan IPv6 pada PD. Pumas Jaya Menggunakan Metode Manual Tunneling. ComTech, 1 (2), 711-722.

[4] Elgili, M., (2014). Comparison between OSPFv3 and OSPFv2. Scientific Research, 6 (1), 43 - 48.

[5] KOMINFO. (2011). Ancaman Sangat Serius Mengenai Habisnya Alokasi Blok Alamat IPv4 di Tingkat Global, Jakarta.

[6] Misra, A., \& Chawia, H., (2016). Performance Analysis of IPv6 Dual-Protocol Stack and Tunnel Transition. International Journal of Science, Engineering and Technology Research (IJSETR), 5 (5), 1494 - 1499.

[7] Rafiudin, R. (2005). IPv6 Addressing. Jakarta : Kelompok Gramedia.

[8] Sangsari, A., Isnawaty, Aksara, LM. F., (2016). Analisis QoS (Quality of Service) Pada Layanan Video Streaming Yang Menggunakan Protokol RTMP (Real Time Messaging Protocol). semanTik, 2(1), 177-188.

[9] Sharma, S., \& Kumar, D., (2015). A Simulation Based Analysis of IPv4, IPv6 Migration Techniques, International Journal of Science, Engineering and Technology Research (IJSETR), 4 (6), 1931 - 1934.

[10] XiaoHong, L., (2013) The Research of Network Transitional Technology from IPv4 to IPv6. Institute of Electrical and Electronics Engineers (IEEE), 1507 - 1509. 